artery disease merely to confirm the diagnosis. Angiography is essential for the preoperative evaluation of patients being considered for bypass surgery and should be reserved for patients most likely to benefit from treatment of this type. This includes those with severe symptoms which fail to respond adequately to antianginal drugs. ${ }^{20}$ Unfortunately, severity of symptoms is not closely related to the extent of coronary artery disease, ${ }^{21}$ and selection of patients for angiography on this basis alone tends to ignore the proved benefit of bypass surgery (in terms of mortality) for subgroups with triple vessel or left main artery disease. ${ }^{12}$ Exercise electrocardiography has been recommended for identification of these high risk subgroups: severely restricted exercise tolerance, exaggerated ST segment depression, and an abnormal response of the blood pressure are predictors of extensive coronary artery disease and a poor prognosis. ${ }^{22-24}$

Unfortunately, the specificity of these predictive variables is not matched by a similar level of sensitivity, ${ }^{4}$ and reliance on non-invasive tests for prognostic guidance ensures that some high risk patients will be overlooked. Indeed, only coronary angiography itself can accurately identify these patients at high risk and provide a less arbitrary selection standard for coronary bypass surgery. At present, resources are not available to underwite a policy of angiography for all patients with suspected coronary artery disease. ${ }^{25}$ Rigorous selection is therefore essential based on an individualised assessment of diagnostic probability and the predicted benefit of bypass surgery.

ADAM D TIMMIS

Senior Registrar,

Department of Cardiology,

Guy's Hospital,

London SE1 9RT

1 European Coronary Surgery Study Group. Long-term results of prospective randomised study of coronary artery bypass surgery in stable angina pectoris. Lancet 1982;ii:1173-80.

2 Veterans Administration Coronary Artery Bypass Surgery Cooperative Study Group. Eleven-year survival in Veterans Administration randomised trial of coronary bypass surgery for stable angina. N Engl f Med 1984;311:1333-9.

3 Passamani E, Davis KB, Gillespie MJ, Killip T, and CASS Principal Investigators and their assamani E, Davis KB, Gillespie MJ, Killip T, and CASS Principal Investigators and their
Associates. A randomised trial of coronary artery bypass surgery. Survival of patients with a low

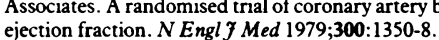

5 Ledley RGF, Lusted LB. Reasoning foundations of medi : diagnosis. Science 1959; 130:9-13.

6 Vecchio TJ. Predictive value of a single diagnostic test in unselected populations. N Engl I Med 1966;274:1171-3.

7 Epstein SE. Implications of probability analysis on the strategy used for noninvasive detection of coronary artery disease. Role of single or combined use of exercise electrocardiographic testing, radionuclide cineangiography and myocardial perfusion imaging. Am $\mathcal{f}$ Cardiol 1980;46:491-9.

8 Detry J-MR, Kapita BM, Cosyns J, Sottiaux B, Brasseur LA, Rousseau MF. Diagnostic value of history and maximal exercise electrocardiography in men and women suspected of coronary heart disease. Circulation 1977;56:756-61.

9 Melin JA, Piret LJ, Vanbutsele RJM, et al. Diagnostic value of exercise electrocardiography and thallium myocardial scintigraphy in patients without previous myocardial infarction: a Bayesia approach. Circulation 1981;63:1019-24.

10 Detrand R, Yiannikas J, Salcedo EE, et al. Bayesian probability analysis: a prospective demonstration of its clinical utility in diagnosing coronary disease. Circulation 1984;69:541-7.

11 Wagner HN Jr. Bayes' theorem: an idea whose time has come? Am $f$ Cardiol 1982;49:875-7.

12 Hlatky M, Botvinick E, Brundage B. Diagnostic accuracy of cardiologists compared with probability calculations using Bayes' rule. Am f Cardiol 1982;49:1927-31.

probability calculations using Bayes' rule. Am f Cardiol 1982;49:1927-31.
13 Diamond GA, Forrester JS, Hirsch M, et al. Application of conditional probability analysis to the Diamond GA, Forrester JS, Hirsch M, et al. Application of conditional probabity
clinical diagnosis of coronary artery disease. $\mathcal{F}$ Clin Invest 1980;65:1210-21.

14 Patterson RE, Eng C, Horowitz SF, Gorlin R, Goldstein SR. Bayesian comparison of costeffectiveness of different clinical approaches to diagnose coronary artery disease. Foumal of the American College of Cardiology 1984;4:278-89.

15 Melin JA, Wijns W, Vanbutsele RJ, et al. Alternative diagnostic strategies for coronary artery disease in women: demonstration of the usefulness and efficiency of probability analysis. Circulation 1985;71:535-42.

16 Patterson RE, Horowitz SF, Eng C, et al. Can exercise electrocardiography and thallium-201 myocardial imaging exclude the diagnosis of coronary artery disease? Bayesian analysis of the clinical limits of exclusion and indications for coronary angiography. Am $\mathcal{f}$ Cardiol 1982 49:1127-35.

17 Lavey EM, Winkel RA. Continuing disability of patients with chest pain and normal coronary arteriograms. F Chron Dis 1979;32:191-6.

18 Ockene IS, Shay MJ, Alpert JS, Weiner BH, Dalen JE. Unexplained chest pain in patients with normal coronary arteriograms. A follow-up study of functional status. $N$ Engl $\mathcal{J}$ Med
$1980 ; 303: 1249-52$.

19 Bass C, Wade C, Hand D, Jackson G. Patients with angina with normal and near normal coronary arteries: clinical and psychosocial state 12 months after angiography. $\mathrm{Br}$ Med $\mathcal{f}$ 1983;287:

20 Ambrose JA. Unsettled indications for coronary angiography. Foumal of the American College of Cardiology 1984;3:1575-80.
21 Bruschke AVG, Proudfit WL, Sones FM. Progress study of 590 consecutive nonsurgical cases of coronary disease followed 5-9 years. Ventriculographic and other correlations. Circulation 1973;47:1154-63.

22 Morris SN, Phillips JF, Jordan JS, McHenry PL. Incidence and significance of decreases in systolic blood pressure during graded treadmill exercise testing. Am f Cardiol 1978; 41:221-7.

23 Sanmarco ME, Pontius S, Selvester RH. Abnormal blood pressure response and marked ischemic ST-segment depression as predictors of severe coronary artery disease. Circulation 1980;61 572-8.

24 Dagenais GR, Rouleau JR, Christen A, Fabia J. Survival of patients with a strongly positive exercise electrocardiogram. Circulation 1982;65:452-6.

25 Williams A. Econmics of coronary artery bypass grafting. Br Med $\mathcal{J}$ 1985;291:326-9.

\section{Landmarks in medicine}

A century ago in the United States scientific medicine scarcely existed. Postgraduate training was woefully undeveloped, and young American physicians seeking experience in research crossed the Atlantic to European centres, particularly in Germany. The foundation of Johns Hopkins Medical School in 1889, the creation of the Rockefeller Institute in the early years of this century, and the reforms in American medical education recommended by Abraham Flexner led to a scientific revolution in medical academic circles that was to establish the United States as the world leader in biomedical science in the modern era.

The fruits of that revolution were illustrated by a series of 51 articles published weekly in the Fournal of the American Medical Association from July 1983 to August 1984 in recognition of its centenary year and now collected into a single volume. ${ }^{1}$ Each of the 51 consists of an article originally published in the journal together with a contemporary commentary by an expert in the subject. The oldest contribution is the original description of dermatitis herpetiformis by Duhring in 1884; the most recent-appropriatelyaddresses that most contemporary of ethical issues, the nature of brain death. They form a truly remarkable collection, which include several contributions by men destined later to receive the accolade of the Nobel prize: Alexis Carrel's pioneer studies on vascular anastomosis and organ transplantation, Simon Flexner's transmission of acute poliomyelitis to monkeys, Peyton Rous's transfer of a malignant new growth with a cell free filtrate were all from the Rockefeller Institute in New York. Achievements from the Boston medical schools included Minot's and Murphy's treatment of pernicious anaemia with a special diet, Castle's classic studies on the intrinsic factor mechanism in the stomach, and the first successful homotransplantation of a kidney between identical twins by Merrill and his colleagues. The United States armed services contributed Walter Reed's immortal and courageous studies on the transmission of yellow fever, the use of penicillin in the treatment of meningitis, and the treatment of acute attacks of vivax malaria with chloroquine.

Fifty-one Landmark Articles in Medicine is a remarkable collection of outstanding firsts; it also includes the original description of Crohn's disease, Blalock and Taussig's pioneer surgical treatment of malformations of the heart, the first surgical ligation of a patent ductus arteriosus, the technique of closed chest cardiac massage developed at Johns Hopkins Hospital, and Blumberg's new antigen in leukaemia sera. The articles prompt two questions. Which real advances are apparent at the time an article is published-and to what extent are such advances recognised only in retrospect?

The collection shows that when an article relates to the introduction of a new and effective method of treatment-as 
with liver treatment in pernicious anaemia or the introduction of insulin or penicillin-the impact is immediate. This is equally true of surgical techniques such as those which have revolutionised the treatment of heart disease or of chronic renal failure. Difficulties arise, however, when no immediate therapeutic result is apparent. Herrick, when he first described the clinical features of sudden obstruction of the coronary arteries at the annual meeting of the American Medical Association in 1912, felt elated as he rose to read his paper for he knew that he had "a substantial contribution to present." It fell as flat as a pancake, and only when electrocardiography became commonplace was his work given the recognition that it so richly deserved. Social mores may also inhibit recognition. Denslow Lewis's remarkable paper "The gynaecological consideration of the sexual act" was presented at the 50th annual meeting of the association in 1899, to be greeted by strong opposition from Howard Kelly from Baltimore for its "elementary physiologic facts" being exposed to a public audience. Charles S Chamberlaine, of Ohio, went further and spoke of his little daughter and how he would "regret to have her taught such things." Only now, 85 years later, has this paper been published in the August pages of the Fournal of the American Medical Association.

Fifty-one Landmark Articles in Medicine is a testimony to the remarkable achievements of medical science in the United States during the past century. American success in this discipline is rightly attributed to the close association of the medical schools with their parent university, an educational model derived from German medicine in the nineteenth century. Would any comparable series of articles be retrievable from the pages of a clinical journal in Britain, where there has rarely been that active invasion of the teaching hospitals by the universities so strongly urged upon Lord Haldane's commission by Sir William Osler? ${ }^{2}$

\section{CHRISTOPHER BOOTH}

Director,

Clinical Research Centre,

Harrow,

Middlesex HAl 3UJ

1 Meyer HS, Lundberg GD. Fifty-one landmark articles in medicine. The fAMA centennial series. Chicago: American Medical Association, 1985.

2 Osler W. Evidence to Royal Commission on University Education in London. London: HMSO, 1910-3. (Chairman Viscount Haldane.)

\section{Resuscitation in hospital: again}

A report describing the poor performance of resuscitation by doctors at a leading teaching hospital may have shocked the public, but it came as little surprise to the medical profession. ${ }^{1}$ Both in Britain ${ }^{2}$ and in the United States ${ }^{3}$ many medical staff are unable to carry out basic life support, cannot intubate and ventilate patients, and are incompetent at handling equipment such as defibrillators. Two questions need to be asked. Why do doctors continue to be lukewarm about resuscitation in hospital, despite the enormous success of campaigns to train members of the public $?^{4}$ And-given the value of the treatment-what can be done to improve doctors' performance?

Current attitudes were reflected at a recent conference on resuscitation at the Royal Free Hospital, London, organised by Tom Evans, one of its cardiologists, and Vera Dallos, an accident and emergency consultant at Whipps Cross Hospital. The interest was so great that the numbers had to be limited to 350 , most of whom were nurses and paramedics. The small number of doctors was striking, and a workshop on the second day devoted to practical training attracted fewer than 40. Andrew Marsden, an accident and emergency consultant at Pinderfields Hospital, Wakefield, and present chairman of the Resuscitation Council (UK) (c/o Department of Anaesthetics, Hammersmith Hospital, London W12 0HS), reported that he had had to cancel a meeting for doctors this autumn because there had been only one application.

Some doctors may argue that they do not need formal teaching-they will be able to cope when the time comes. A more important reason for the lack of interest, however, may be lack of leadership from above. Many senior consultants were trained before resuscitation in hospital became routine; a survey of their skills would almost certainly find similar inadequacies to those of their juniors. This attitude should change as the older consultants are replaced provided that their successors are properly trained.

Emotional issues and lack of consensus about who to resuscitate add to the uncertainties. Death in hospital is still regarded as "cardiac arrest" and the meeting was told that some consultants still insist that all patients should be resuscitated. Doctors, said Peter Baskett, an anaesthetist from Bristol, refuse to acknowledge end stage disease in otherwise healthy elderly people. All speakers endorsed the view that careful decisions not to resuscitate, taken in advance and after full consultation, were increasingly acceptable to the public and to the caring professions. And the patient should be brought into this decision if he or she wishes.

The resuscitation Council (UK) is measuring the outcome of hospital resuscitation. It would be valuable if its members could prote the attitudes of junior medical staff towards the procedure. When visiting hospitals to inspect training posts I make a point of asking junior staff about this aspect of their work. Most express the expected anxiety, but many also find it unpleasant, messy, and undignified; they are frequently frustrated by equipment that does not work properly, and they question whether the results justify the effort expended.

How, then, can training - and hence morale-be improved? If you want to be proficient, said Marsden, start young-children love it. Public campaigns are successful because of catchy advertising, videos (one of which has a voice over by Orson Welles), and certificates of competence. In a sense it is almost too late to start when an individual becomes a medical student, but Evans has successfully established compulsory first aid sessions in the first year with an examination, followed by updates during the introductory clinical course, the attachment to anaesthetics, and in the final year. Eight of the London medical schools have developed such formal courses.

The message needs to be reinforced continually, and when the doctor reaches the district hospital he or she should expect an induction day for newly arrived staff on resuscitation procedures and a room where practical experience can be obtained by using simulators (Laerdal Medical Training Aids and Equipment, Orpington, Kent BR6 0EG). ${ }^{5}$ Doctors should not be put off by the complexities that experts argue about; the principles of cardiopulmonary resuscitation are simple and may be embodied, for example, in flow charts obtainable from the Resuscitation Council (UK). David Zideman, an anaesthetist from Hammersmith Hospital, 